\title{
KOREKTOR FAKTOR DAYA OTOMATIS PADA INSTALASI LISTRIK RUMAH TANGGA
}

\author{
Yuniarto, Eko Ariyanto \\ Program Studi Diploma III Teknik Elektro \\ Sekolah Vokasi Universitas Diponegoro
}

\begin{abstract}
Yuniarto, Eko Ariyanto, in this paper explain that TL lamps, electric motors, Air Conditioner (AC), and other electrical equipment which is widely used for industry and households. Where all the electrical equipment is a burden that is inductive. As a result of the use of an inductive load, causing the falling value of the electrical power factor mounted on the customer can not be used optimally. To overcome this, in this thesis, has created a tool to correct the power factor value automatically. To improve the power factor, is used capacitors mounted in parallel to the load. By using the integrator, it can be obtained how large capacitor must be mounted parallel to the load according to the inductive load changes resulting in improved power factor value. Test results showed that an increase in the value of power factor from 0.34 to 0.95 .
\end{abstract}

Keyword: power factor, capasitor, inductive load, integraton

\section{PENDAHULUAN}

Pemakaian beban induktif oleh pelanggan listrik untuk rumah tangga memang tidak bisa terhindar, karena banyak peralatan listrik semisal AC, kipas angin, lampu TL, pompa air dan lain-lain merupakan beban induktif. Akibat dari pemakain beban induktif ini akan membuat turunnya nilai faktor daya, sehingga dapat membuat kapasitas daya listrik yang terpasang pada pelanggan tidak dapat digunakan secara optimal. Banyak pelanggan listrik melakukan penambahan daya jika kapasitas daya yang terpasang dirasa kurang mencukupi kebutuhan. Padahal jika kapasitas daya yang terpasang dapat optimal, opsi penambahan daya tidak perlu dilakukan.

Banyak cara yang digunakan untuk memperbaiki faktor daya, salah satunya adalah dengan menambahkan kapasitor. Di kalangan industri perbaikan faktor daya dengan menggunakan kapasitor ini telah banyak digunakan. Akan tetapi jarang digunakan pada kalangan rumah tangga. Pada umumnya faktor daya yang dijual dipasaran untuk keperluan rumah tangga hanya terdiri dari sebuah kapasitor. Sedangkan faktor daya yang dihasilkan berubah-ubah, hal ini disebabkan karena beban listrik pada rumah tangga juga berubah-ubah pula.

Untuk mengatasi masalah tersebut, pada penelitian ini, dibuatlah sebuah alat yang dapat memperbaiki faktor daya secara otomatis sesuai beban induktif yang berubah-ubah dengan menggunakan integrator untuk menentukan besarnya kompensasi (kapasitor) yang harus dipasang paralel terhadap terjadinya perubahan beban induktif.

\section{DASAR TEORI \\ Pengertian Daya}

Daya adalah energi yang dikeluarkan untuk melakukan usaha. Dalam sistem tenaga listrik daya merupakan jumlah energi yang digunakan untuk melakukan kerja atau usaha. Daya listrik biasanya dinyatakan dalam satuan Watt atau Horsepower (HP), Horsepower merupakan satuan daya listrik dimana 1 HP setara 746 Watt atau lbft/second. Sedangkan Watt merupakan unit daya listrik dimana 1 Watt memiliki daya setara dengan daya yang dihasilkan oleh perkalian arus 1 Ampere dan tegangan 1 Volt.

Daya dinyatakan dalam $\mathrm{P}$, tegangan dinyatakan dalam $\mathrm{V}$ dan arus dinyatakan dalam I, sehingga besarnya daya dinyatakan :

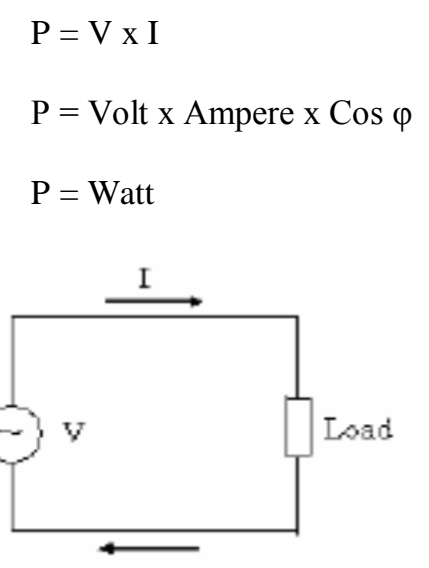

Gambar 1. Arah Aliran Arus Listrik

\section{Daya Aktif}

Daya aktif (active power) adalah daya yang terpakai untuk melakukan energi sebenarnya. Satuan daya aktif adalah Watt. Misalnya energi panas, cahaya, mekanik dan lain-lain. Rumus dari daya aktif adalah:

$$
\mathbf{P}=\text { V. I. } \operatorname{Cos} \varphi
$$

Daya ini digunakan secara umum oleh konsumen dan dikonversikan dalam bentuk kerja. 


\section{Daya Reaktif}

Daya reaktif (reactive power) adalah jumlah daya yang diperlukan untuk pembentukan medan magnet. Dari pembentukan medan magnet maka akan terbentuk fluks medan magnet. Contoh daya yang menimbulkan daya reaktif adalah transformator, motor, lampu TL dan lain-lain. Satuan daya reaktif adalah VAR.

$$
\begin{aligned}
& \mathrm{Q}=\mathrm{V} \cdot \mathrm{I} \cdot \operatorname{Sin} \varphi \\
& \mathrm{Q}=\sqrt{S^{2}+P^{2}} \\
& \mathrm{Q}=\frac{\mathrm{E}^{2}}{\mathrm{X}}
\end{aligned}
$$

\section{Daya Semu}

Daya Semu (apparent power) adalah daya yang dihasilkan oleh perkalian antara tegangan rms dan arus rms dalam suatu jaringan atau daya yang merupakan hasil penjumlahan trigonometri daya aktif dan daya reaktif. Satuan daya semu adalah VA. Rumus daya semu adalah :

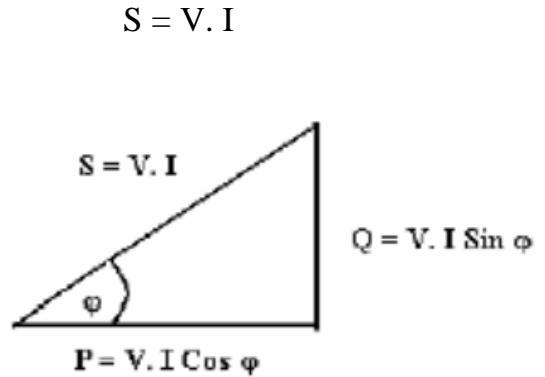

Gambar 2. Penjumlahan Trigonometri Daya Aktif, Reaktif Dan Semu

\section{Sifat Beban Listrik}

Dalam suatu rangkaian listrik selalu dijumpai suatu sumber dan beban. Bila sumber listrik DC, maka sifat beban hanya bersifat resistif murni, karena frekuensi sumber DC adalah nol.

Reaktansi induktif $\left(\mathrm{X}_{\mathrm{L}}\right)$ akan menjadi nol yang berarti bahwa induktor tersebut akan short circuit. Reaktansi kapasitif $\left(\mathrm{X}_{\mathrm{C}}\right)$ akan menjadi tak terhingga yang berarti bahwa kapasitif tersebut akan open circuit. Jadi sumber DC akan mengakibatkan beban induktif dan beban kapasitif tidak akan berpengaruh pada rangkaian. Bila sumber listrik AC maka beban dibedakan menjadi tiga yaitu beban resistif, beban induktif, beban kapasitif.

\section{Beban Resistif}

Beban resistif yang merupakan suatu resistor murni. contoh: lampu pijar, pemanas. Beban ini hanya menyerap daya aktif dan tidak menyerap daya reaktif sama sekali. Apabila pada beban resistif murni dialiri arus listrik bolak-balik, maka arus dan tegangan tersebut akan sefasa (berimpit) (Eminister,1994). Secara matematis dinyatakan:

$$
\mathrm{R}=\frac{\mathrm{V}}{\mathrm{I}}
$$

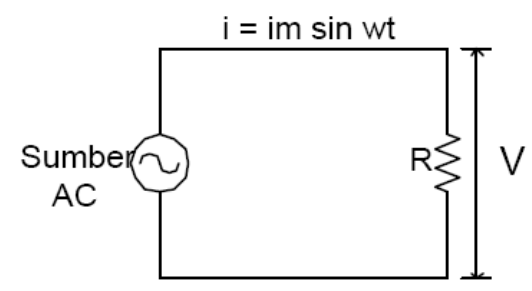

Gambar 3. Rangkaian Beban Resistif

Gambar 4. memperlihatkan grafik yang melukiskan tegangan bolak-balik dan kuat arus listrik bolak-balik dalam suatu system koordinat yang sama.

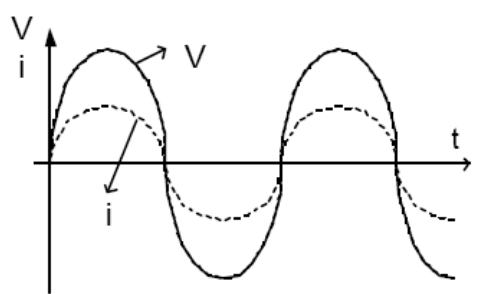

Gambar 4. Hubungan Fasa Antara Arus Dan Tegangan Pada Beban Resistif

Dari gambar 4 tampak bahwa V dan I mencapai nilai maksimum, nol dan minimum pada saat yang bersamaan. Pada keadaan demikian, dikatakan bahwa V dan I mempunyai fase yang sama (sefase).

Cara lain untuk memperlihatkan hubungan antara $\mathrm{V}$ dan i dapat dilakukan dengan melukiskan dengan diagram phasor, seperti yang diperlihatkan dalam gambar 5 .

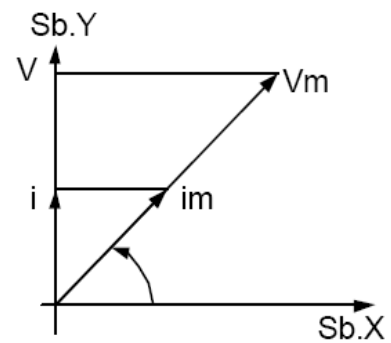

Gambar 5. Diagram Phasor Hubungan V dan I Rangkaian Resistor

\section{Beban Induktif}

Beban induktif adalah beban yang mengandung kumparan kawat yang dililitkan pada sebuah inti besi, contoh: motor-motor listrik, induktor dan transformator. Beban ini mempunyai faktor daya antara $0-1$ "lagging". Beban ini 
menyerap daya aktif (W) dan daya reaktif (VAR). Tegangan mendahului arus sebesar $\varphi^{\circ}$. Secara matematis dinyatakan:

$$
\mathrm{X}_{\mathrm{L}}=2 \pi \mathrm{f} . \mathrm{L}
$$

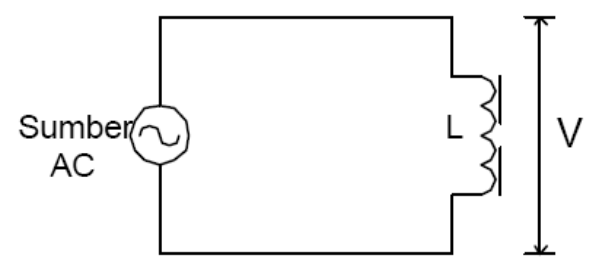

\section{Gambar 7. Rangkaian Beban Induktif}

Gambar 8 melukiskan diagram hubungan antara $\mathrm{V}$ dan I untuk rangkaian induktor $\mathrm{L}$ dalam sebuah sistem koordinat yang sama.

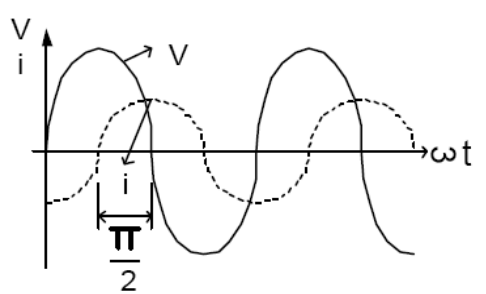

\section{Gambar 8. Hubungan Fasa Antara Arus Dan} Tegangan Pada Beban Induktif

Dengan grafik tersebut, tampak bahwa V dan i berbeda fase sebesar $\pi / 2$. Dalam diagram phasor, hubungan $\mathrm{V}$ dan i untuk rangkaian induktor dapat dilihat pada gambar dibawah ini

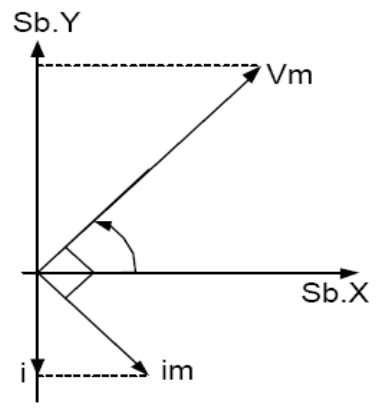

\section{Gambar 9. Diagram Phasor V dan i Rangkaian Induktor}

\subsubsection{Beban Kapasitif}

Beban kapasitif adalah beban yang mengandung suatu rangkaian kapasitor. Beban ini mempunyai faktor daya antara $0-1$ "leading". Beban ini menyerap daya aktif (W) dan mengeluakan daya reaktif (VAR). arus mendahului tegengan sebesar $\varphi^{\circ}$. Secara matematis dinyatakan:

$$
\mathrm{X}_{\mathrm{C}}=\frac{1}{2 \pi \mathrm{fC}}
$$

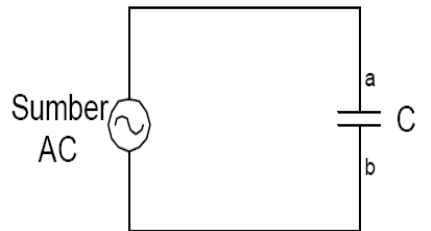

\section{Gambar 10. Rangkaian Beban Kapasitif}

Grafik V dan i untuk rangkaian kapasitor digambarkan dalam sebuah sistem koordinat yang sama, maka akan diperoleh kurva tegangan dan arus seperti tampak pada gambar dibawah ini.

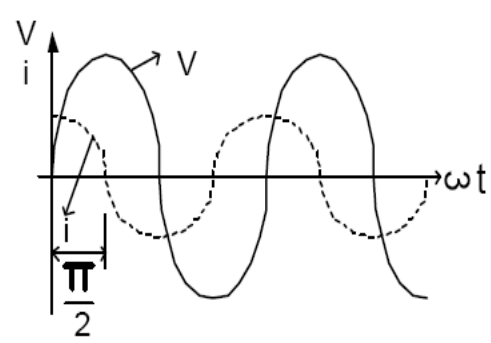

\section{Gambar 11. Hubungan Fasa Antara Arus Dan Tegangan Pada Beban Kapasitif}

Dari gambar 11 di atas tergambarkan bahwa $\mathrm{V}$ dan i berbeda fase $\pi / 2$, yaitu arus i mendahului $\mathrm{V}$ sebesar $\pi / 2$. Diagram phasor untuk rangkaian kapasitor $\mathrm{C}$ dapat digambarkan seperti pada gambar 12 sebagai berikut.

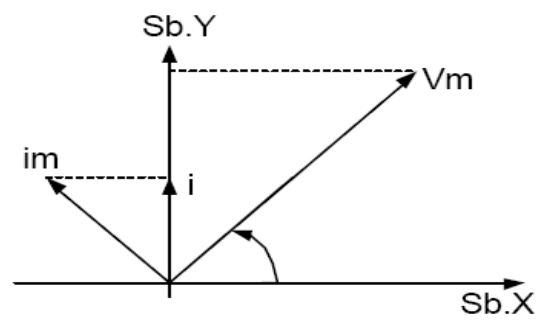

\section{Gambar 12. Diagram Phasor V dan i Rangkaian Kapasitor}

\subsection{Segitiga Daya}

Segitiga daya merupakan segitiga yang menggambarkan hubungan matematika antara tipetipe daya yang berbeda (apparent power, active power, reactive power) berdasarkan prinsip trigonometri. 


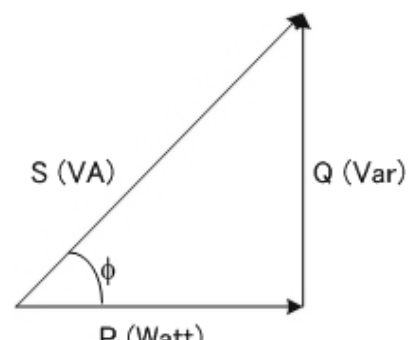

$\mathrm{P}$ (Watt)

Gambar 7. Diagram Segitiga Daya

Dimana berlaku hubungan:

$$
\begin{aligned}
& \mathrm{S}=\sqrt{P^{2}+Q^{2}} \\
& \mathrm{~S}=\mathrm{V} . \mathrm{I} \\
& \mathrm{P}=\mathrm{S} \operatorname{Cos} \varphi \\
& \mathrm{Q}=\mathrm{S} \operatorname{Sin} \varphi
\end{aligned}
$$

\section{Faktor daya}

Faktor daya $(\operatorname{Cos} \varphi)$ dapat didefinisikan sebagai rasio perbandingan antara daya aktif (Watt) dan daya semu (VA) yang digunakan dalam sirkuit AC atau beda sudut fasa antara V dan I yang biasanya dinyatakan dalam $\operatorname{Cos} \varphi$.

$$
\begin{aligned}
\text { Faktor daya }= & \frac{\text { Daya Aktif }(\mathrm{P})}{\text { Daya Semu (S) }} \\
& =\frac{\mathrm{W}}{\mathrm{VA}} \\
& =\frac{\text { V.I } \operatorname{Cos} \varphi}{\text { V.I }} \\
& =\operatorname{Cos} \varphi
\end{aligned}
$$

Faktor daya mempunyai nilai range antara 0 - 1 dan dapat juga dinyatakan dalam persen. Faktor daya yang bagus apabila bernilai mendekati satu.

$$
\begin{aligned}
\operatorname{Tan} \varphi= & \frac{\text { Daya Reaktif }(\mathrm{Q})}{\text { Daya Aktif }(\mathrm{P})} \\
& =\frac{\mathrm{VAR}}{\mathrm{W}}
\end{aligned}
$$

Karena komponen daya aktif umumnya konstan (komponen VA dan VAR berubah sesuai dengan faktor daya), maka dapat ditulis seperti berikut:

$$
\text { Daya Reaktif }(\mathrm{Q})=\frac{\text { Daya Aktif }(\mathrm{P})}{\operatorname{Tan} \varphi}
$$

\section{Perbaikan Faktor Daya}

Dalam sebuah sumber arus bola balik, bila beban yang diaplikasikan bersifat resistif murni, maka gelombang tegangan dan arus adalah sefasa seperti yang diperlihatkan gambar 8 .

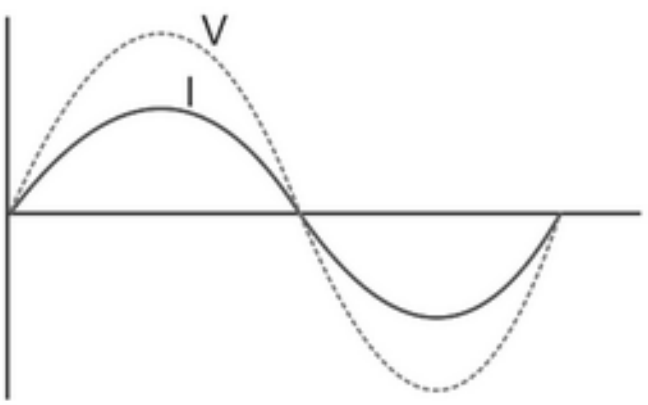

Gambar 8. Beban Resistif

Beban yang bersifat induktif atau kapasitif dapat menggeser persilangan nol antara tegangan dan arus. Bila bebannya merupakan beban induktif persilangan nol gelombang arus muncul beberapa saat setelah persilangan nol gelombang tegangan muncul. Hal ini biasa dikatakan sebagai arus tertinggal.

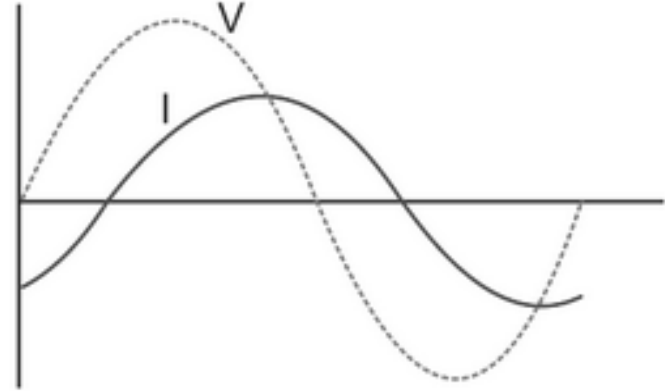

Gambar 9. Beban Induktif
Sebaliknya untuk arus beban yang bersifat kapasitif, persilangan nol gelombang arus akan muncul beberapa saat sebelum persilangan nol gelombang tegangan. Hal ini biasa dikatakan sebagai arus mendahului.

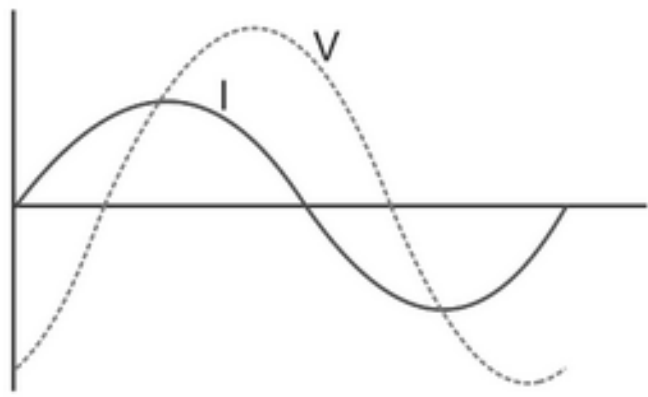

Gambar 10. Beban Kapasitif

Sebuah kapasitor daya atau yang dikenal dengan nama kapasitor bank harus mempunyai daya $\mathrm{Q}_{\mathrm{C}}$ yang sama dengan daya reaktif dari system yang akan diperbaiki faktor dayanya. Jika keadaan ini dipenuhi, kapasitor bank akan memperbaiki faktor daya menjadi bernilai maksimum (faktor daya $=1$ ). Besarnya daya reaktif yang diperlukan untuk mengubah faktor daya dari $\cos \varphi_{1}$ menjadi $\cos \varphi_{2}$ dapat ditentukan dengan: 


$$
\mathrm{Qc}=\mathrm{P} \times\left(\tan \theta_{1}-\tan \theta_{2}\right)
$$

Keterangan :

$\begin{array}{ll}\mathrm{P} & \text { : Daya Aktif (Watt) } \\ \mathrm{Qc} & \text { : Daya Reaktif Kompensator (VAR) } \\ \theta_{1} & \text { : Sudut sebelum diperbaiki } \\ \theta_{2} & \text { : Sudut setelah diperbaiki }\end{array}$

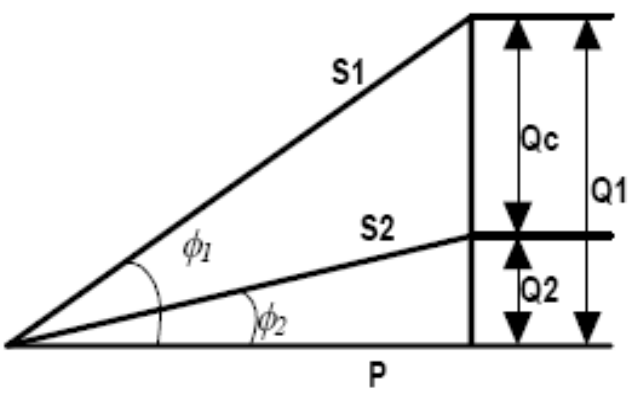

Gambar 11. Prinsip Perbaikan Faktor Daya

Untuk menghitung ukuran kapasitor yang diperlukan untuk melawan dampak dari faktor daya yang tertinggal, dengan cara menurunkan dalam persamaan sebagai berikut :

$$
\begin{aligned}
& Q c=\frac{E^{2}}{X c} \\
& X c=\frac{E^{2}}{Q c} \\
& C=\frac{1}{2 \pi f \cdot X c}
\end{aligned}
$$

\section{Keterangan:}

Qc : Daya Reaktif Kompensator (VAR

Xc : Hambatan Kompensator (Ohm)

E : Tegangan Listrik (V)

f : Frekuensi Listrik (Hz)

\section{PERANCANGAN ALAT}

Blok Diagram

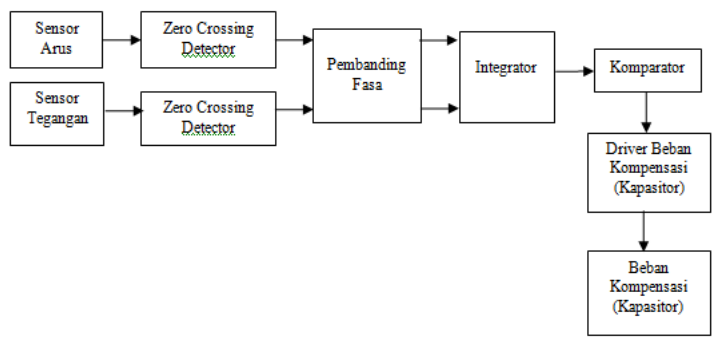

Gambar 12. Blok diagram

\section{Dasar Alat yang Dibuat}

Sinyal kondisioner dari jala-jala listrik masuk ke sensor arus dan sensor tegangan. Sinyal kondisioner ini berupa gelombang sinus. Sinyal keluaran dari sensor tegangan berupa gelombang sinus terpenggal, amplitudo tetap. Selanjutnya kedua sinyal dari sensor tegangan dan arus diubah menjadi gelombang kotak agar bisa diterima oleh rangkaian pembanding fasa. Untuk mengubah gelombang sinus menjadi gelombang kotak dibutuhkan rangkaian zero crossing detector yaitu rangkaian yang mengubah sinyal sinusoida menjadi gelombang kotak.

Rangkaian pembanding fasa mempunyai dua input dan dua output. Masukan dari rangkaian pembanding fasa berupa gelombang kotak dari sensor arus dan sensor tegangan. Karena beban cenderung induktif atau arus ketinggalan berarti sinyal dari sensor arus ketinggalan dari sinyal sensor tegangan. Sinyal sensor tegangan akan menset satu dari rangkaian pembanding fasa dan output akan direset apabila disusul masukan dari sinyal sensor arus.

Sinyal output rangkaian pembanding fasa akan menuju integrator. Integrator ini membuat beda waktu antara sinyal dari sensor arus dan sensor tegangan. Semakin lama sinyal dari sensor arus maka tegangan output pembanding fasa akan tinggi, begitu juga sebaliknya. Dan apabila sefasa maka tegangan output akan konstan.

Tegangan output integrator akan diproses dengan komparator untuk menentukan besar kompensasi yang diberikan. Apabila tegangan masukan komparator lebih tinggi dari tegangan referensi maka tegangan keluaran akan bernilai high dan menyalakan driver relay, begitu juga sebaliknya, apabila tegangan input lebih rendah dari tegangan referensi maka output komparator akan bernilai low.

Driver relay ini akan menghubungkan kapasitor pada jala-jala listrik sehingga beban akan bersifat kapasitif akibat adanya kapasitor. Pada saat jaringan bersifat kapasitif maka sensor tegangan dan sensor arus akan membaca perubahan fasa ini sehingga komparator akan menentukan berapa banyak kapasitor yang akan dibutuhkan 


\section{HASIL PENGUKURAN}

Dari alat dibuat yang telah dibuat kemudian dilakukan uji coba menggunakan beban lampu TL dengan besar beban yang bervariasi yaitu $1 \times 15 \mathrm{~W}$, $2 \times 15 \mathrm{~W}, 3 \times 15 \mathrm{~W}$, dan 4 x $15 \mathrm{~W}$.

Dari hasil pengukuran didapatkan data-data seperti pada tabel 1 dan 2 .

Hasil pengukuran diatas didapat bahwa arus listrik yang mengalir sebelum dipasang kapasitor lebih besar daripada arus listrik pada saat dipasang kapasitor. Sedangkan untuk faktor daya terjadi kenaikan nilai faktor daya yang semula $0,34-0,36$ menjadi $0,90-0,95$.

Tabel 1. Pengukuran Sinyal Sensor

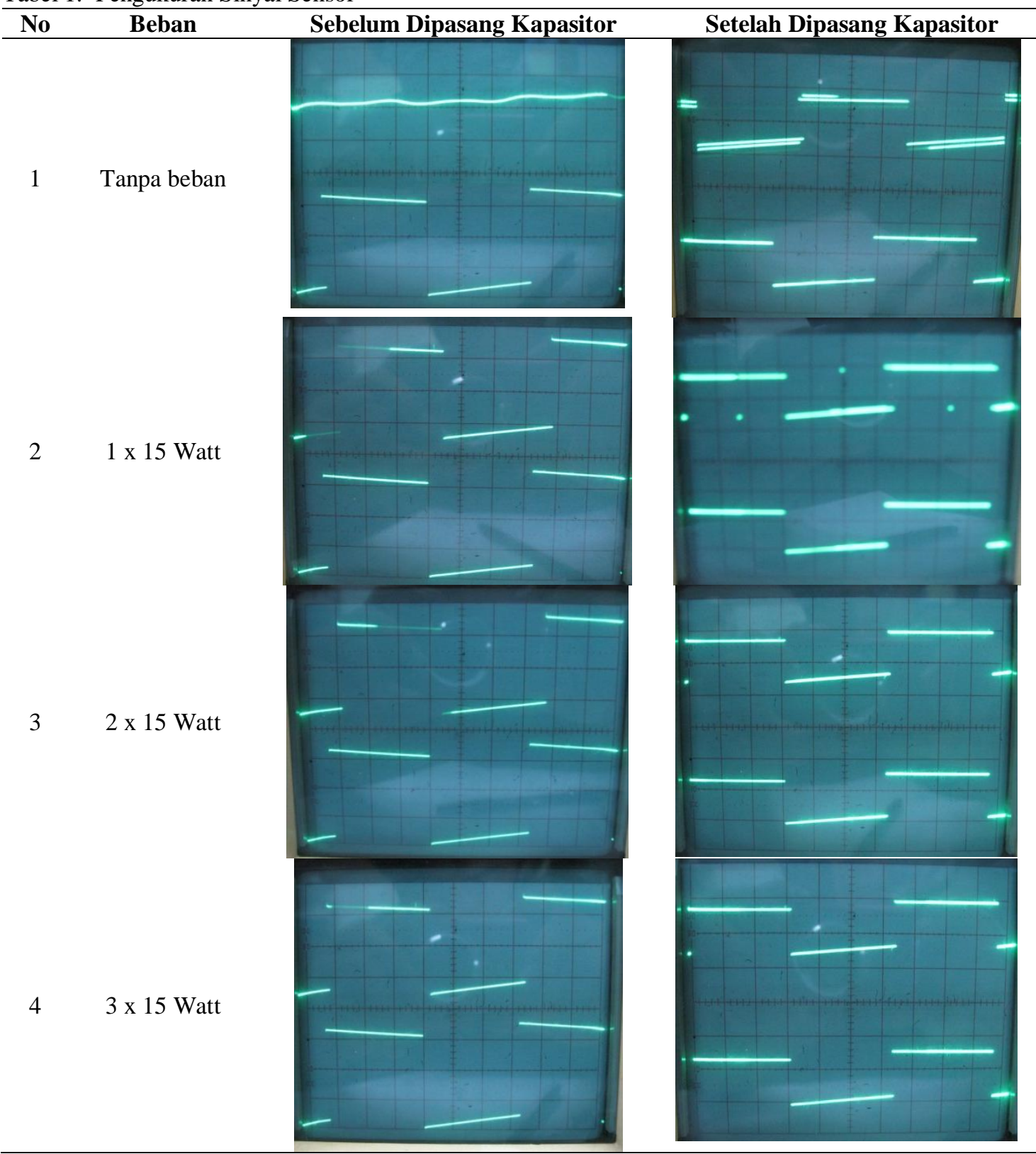




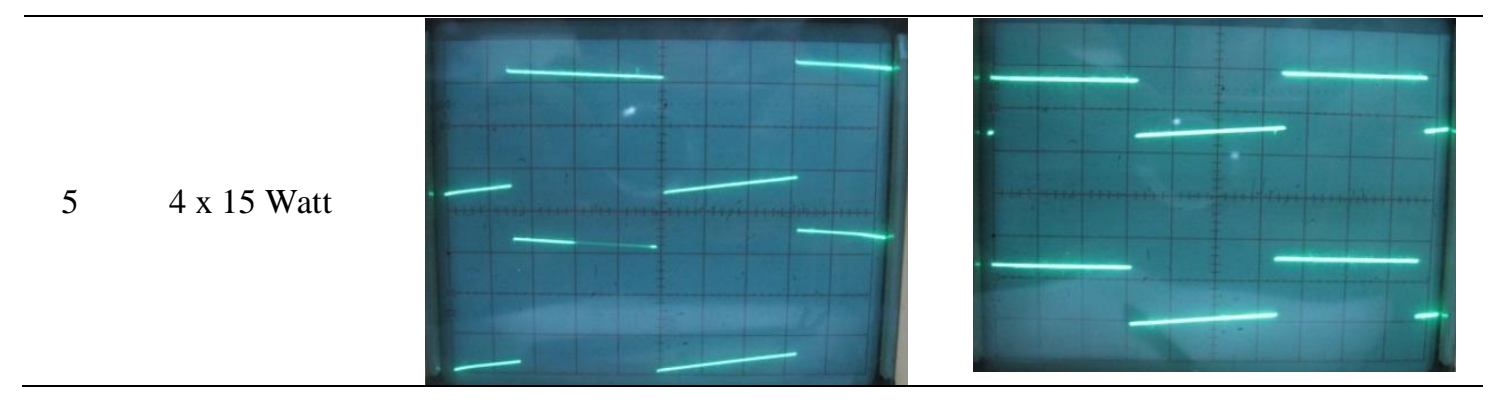

Tabel 2. Pengukuran Arus dan Faktor Daya

\begin{tabular}{cccccc}
\hline \multirow{2}{*}{ No } & \multirow{2}{*}{ Beban } & \multicolumn{2}{c}{ Sebelum Dipasang C } & \multicolumn{2}{c}{ Setelah Dipasang C } \\
\cline { 3 - 6 } & & Arus (A) & Cosphi & Arus (A) & Cosphi \\
\hline 1 & 1 x 15 Watt & 0,22 & 0,35 & 0,08 & 0,95 \\
2 & 2 x 15 Watt & 0,44 & 0,34 & 0,15 & 0,90 \\
3 & 3 x 15 Watt & 0,66 & 0,35 & 0,22 & 0,92 \\
4 & 4 x 15 Watt & 0,88 & 0,36 & 0,30 & 0,91 \\
\hline
\end{tabular}

\section{KESIMPULAN}

- Sensor fasa tegangan dan fasa arus dapat bekerja dengan baik seperti yang terlihat di tabel 4.1.

- Alat yang dibuat bisa bekerja dengan baik, yang ditandai dengan cos phi yang cenderung tetap meskipun beban berubah.

- Perubahan cos phi cukup significant yang diikuti juga dengan perubahan arus yang cukup significant pada saat sebelum diberi kapasitor dan sesudah diberi kapasitor.

\section{DAFTAR PUSTAKA}

1. Bishop, Owen. 2004. Electronics a first Course. (diterjemahkan oleh: Irzam Harmein). Jakarta: Erlangga

2. Calyton, George, Steve winder. 2005. Operational Amplifiers. Edisi Kelima. (diterjemahkan oleh: Wiwit Kastawan). Jakarta: Erlangga.

3. Coughlin, Robert F., Frederick F. Driscoll. 1983. Operational Amplifiers and Linear Integrated Circuits. Edisi Kedua. (diterjemahkan oleh: Herman Widodo Soemitro). Jakarta: Erlangga.

4. Fauzan. Pembuatan dan Pengujian Modul Beban Tak Seimbang. http://isjd.pdii.lipi.go.id/admin/jurnal/5108374 $\underline{0 . p d f}$ 